\title{
The Role of Electronic Payments in Business development in Rwanda (EPPD)
}

\author{
Nshunguye Justin ${ }^{1}$, Isaac Tumwine ${ }^{2}$, Hakizimana Cesar ${ }^{3}$ \\ Department of Information Technology, University of Tourism, Technology and Business studies, Rwanda ${ }^{1}$ \\ A student in Masters of Control Science and Engineering specializing in Artificial intelligence in Beijing University of \\ Civil Engineering and Architecture in the school of Electrical and information Engineering, China Mainland. \\ Xicheng and Daxing Campus ${ }^{2}$ \\ Department of Business Information Technology, University of Tourism, Technology and Business studies, Rwanda ${ }^{3}$

\begin{abstract}
The explosion of the Internet and mobile phones, as well as other rapid technological developments, has significantly influenced momentous changes in the payments market. Perceived as being more efficient and less expensive, electronic payments pave the way for the development of more sophisticated digital services in both the public and the private sector. This article provides an overview of electronic payment systems and their relation to recent developments in Rwanda. It summarizes existing card-based stored-value-payment initiatives in Rwanda and presents the current identity management infrastructure in the country as a potential enabler to support the development of a more comprehensive national electronic payment system. The researcher concludes by saying that electronic transfer funds have been around for many years and the economy has greatly benefited from this technological advance. An electronic payment system such as credit cards has facilitated monetary transactions and even provides a way to finance everyday purchases through credit.
\end{abstract}

Keywords: e-payment, transactions, online, ATMs

\section{I.INTRODUCTION TO THE STUDY}

Since the overcoming of barter trade in the history of mankind, trade usually involves the exchange of goods and equivalent abstract values, such as money. Over years, many variants have been introduced of how to pay and thereby handing over monetary values in commercial relationships, e.g., cash as coins, cash as banknotes or early paper-based credit card payments. This was before electronic payment systems. With the dispersal of digitalization and the availability of communication networks, a large number of electronic payment systems have been proposed and developed which provide new means for the representation of values. Electronic payments may be defined as an electronic value transfer of a payment from the payer to the recipient through an electronic payment mechanism.

The e-payment service comes with a web-based user interface that allows customers to access, manage their bank accounts and transactions remotely. In general, e-payment refers to electronic payment in the context of e-commerce online transactions conducted over the Internet. Electronic payments can also be defined as a paperless payment process. One of the most popular payment forms online are credit and debit cards. Besides them, there are also alternative payment methods, such as bank transfers, electronic wallets, smart cards or bit coin wallet. E-commerce grows rapidly and provides an opportunity for companies to increase sales over the Internet. Nowadays, every individual and company familiar with e-commerce to make sales and purchase products and services 


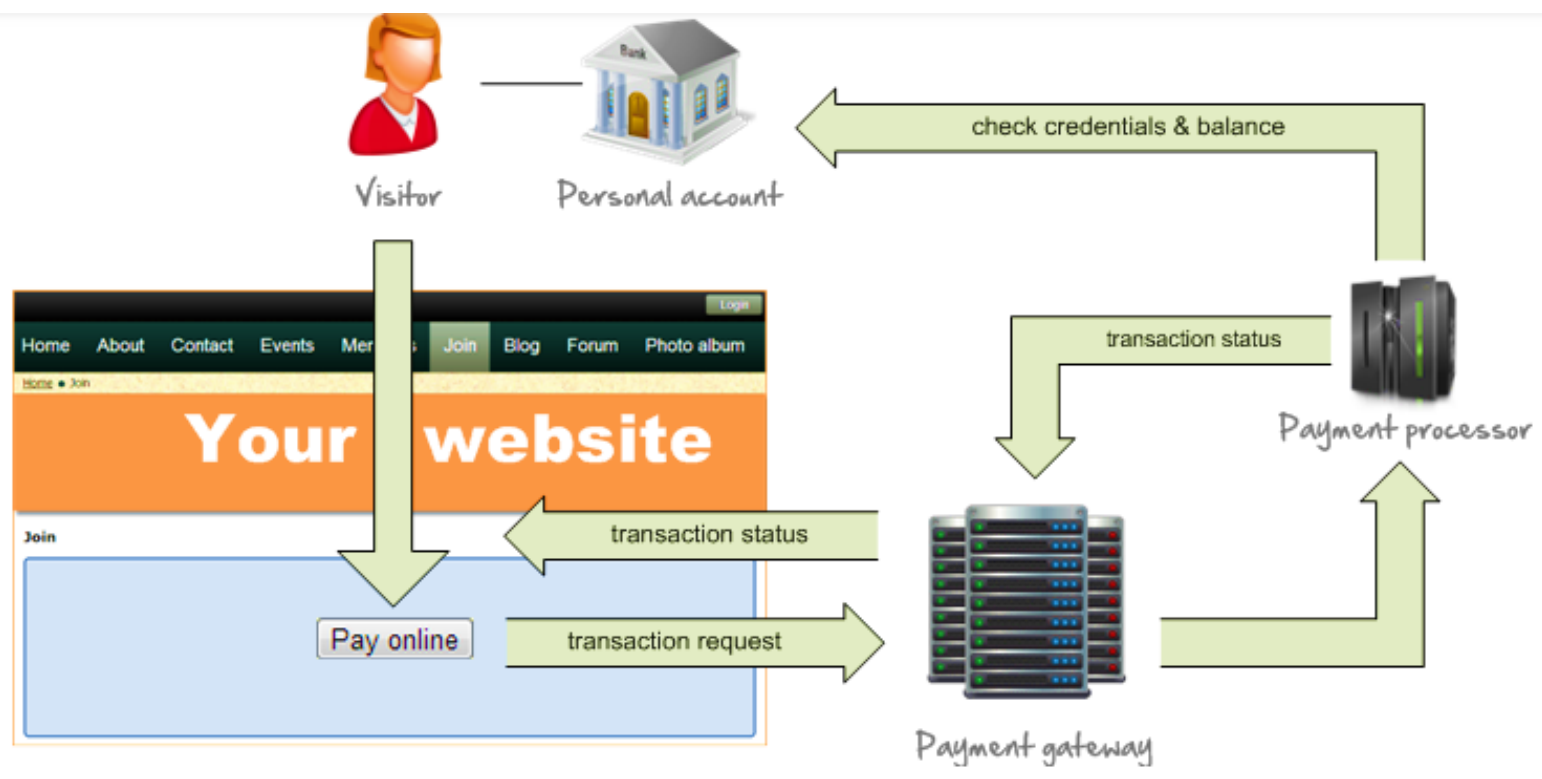

Figure 1: Electronic payment scheme

\section{II.PROBLEM STATEMENT}

Counterfeit currency is a challenge that can slowly hurt an economy of any country, especially a developing country like Rwanda, if not dealt with at an early stage. Communications, information security, access stations, guidance and use support competition, ICT infrastructure and data privacy are one of the main issues in e-payment when their lack of it for example using and accessing the infrastructure as a medium of connecting to this service. Experts say fake or counterfeit money increases prices (inflation) due to more money getting circulated in the economy unauthorized artificial increase in the money supply; leads to decrease in the acceptability of paper money and causes losses to the business community. In Rwanda, this form of economic crime is not practiced on a large scale, although Rwanda National Police (RNP) its strategy is to bring down even the few cases that exist and those involved face justice. Statistics from the Criminal Investigation Department at RNP indicate that between January and April last year, there were 65 cases of counterfeit money handled and investigated by police, involving counterfeits worth Rwf1.6 million and US\$700. Between January and April this year, 111 cases of counterfeit money were registered involving a total amount of counterfeits of Rwf 5.2 million and US\$36,000.

\section{III.RESEARCH OBJECTIVES}

There are several factors that can contribute to user acceptance of an electronic performance support system EPS: innovative and reliable of the technology in Rwanda, effective business practices especially in private sectors, smart marketing and promotion, good usability and a carefully carried out interaction design on national level. This research has been pursuing an interesting and daring task: to explore issues on user acceptance of e-commerce ,awareness on ecommerce, find challenges faced by e-payment in Rwanda by end users so they can be maximized in Rwanda, and the number of joined users will justify the system's rollout and its further development. Without ignoring the importance of marketing, business and technological factors, this research focuses on awareness of electronic payment which can also support e-commerce (EPSs) and how to overcome counterfeit.

\section{IV.LITERATURES REVIEW}

According to the European Central Bank, the proportion of online payments among cashless payment instruments in the European Union is rather low. The report admits that although there has been a lot of discussion on the use of EPSs and their importance "it is still not a widely used medium", [1] The lack of customer demand, the diversity of technological standards and the lack of support by financial institutions are mentioned among the reasons preventing the development of electronic payment systems [2], Some experts estimate that about $85 \%$ of all Internet transactions are done with credit cards that were not originally designed for the Internet[3]. According to a survey by marketing research firm Jupiter Research, credit cards are still the dominant payment method for online purchases, accounting up to $95 \%$ of online transactions in the United States. This demonstrates still low user acceptance of alternative electronic payment systems, designed specifically for e-commerce. 
There are more concerns related to the credit card use in online e-commerce that are responsible for reluctant user's acceptance of credit cards and e-commerce. According to the report published by marketing research firm IDC, [4] almost half of European users of the Internet do not buy goods online because they either do not trust the Web merchants or fear their credit card details will not be secure. According to analysts, total credit card fraud rose to $\$ 4$ billion in 2002 (i.e. $\$ 2$ for every card issued). Industry estimates that the amount of online credit card fraud could be in the $\$ 500$ million range.

Authorities believe that hackers have stolen more than one million credit card numbers from E-commerce sites. It would not be a surprise that many customers use their credit cards with reservations. A survey by Visa of 15 Banks from 12 EU countries in 2002 found that online credit card payments account for nearly half of all complaints. More than one in five of these came from people who had not even shopped on the Internet, but were billed for online transactions [5].

The progress that Rwanda has made so far is testament to how digital transformation can drive economic growth. As the country pushes forward with its development agenda, a cashless vision will play an important role. To achieve this vision it will require that businesses, large and small, public institutions and all Rwandans, embrace e-payments.

\section{V.REGIONAL LANDSCAPE}

Africa's payment landscape has undergone significant changes over the past decade, especially with the proliferation of non-financial institutions such as MNOs, Payment Service Operators (PSO) or Payment Service Providers (PSP), and retailers into the payment industry. In addition, focus on branchless banking initiatives such as mobile banking, transaction and acceptance terminals, and Internet access is now predominant in many African countries. MFS and agent banking, in particular, have become established payment channels through which customers in the African continent conduct remittance and payment transactions. Per GSMA's State of the Industry Report (SOTIR), there were over 227 million registered mobile money accounts in 2016, and over $80 \%$ of the region has deployed mobile money services. Other important trends in the payment landscape include the convergence of e-commerce and mobile payments through the uptake of smartphones and mobile applications; the adoption of e-payment by government organizations to capture revenue (e.g. taxes and utilities) and disburse payments (e.g. pension and social benefits); and the growing cross-border, low-value e-payment market, such as remittances, international bill payment, e-commerce, and trade services.

These trends further underscore the critical need for central banks to take a proactive approach to facilitate a payments landscape that is safe, reliable, efficient, and affordable for end users. As said earlier, governments around the world are prioritizing efforts to move from a cash-based to a cashless economy as one of the key means to drive financial inclusion. 19 countries in Sub-Saharan Africa signed the Maya Declaration, a commitment to the economic and social potential of the 2.5 billion people unbanked through financial inclusion. Access to payment services. Merits of epayment and e-commerce in general include the following:

* It saves time: you will not spend your time going to the market to buy those goods.

* It saves money: sometimes you will save money if you want to buy a car from china you have to go there with a plane (means that you need money to pay) but if you use E-Commerce no need of that money to pay for transport.

* Access many products from different industries: by using e-commerce you can visit different websites without going to their sites or physical place.

* Information: using e-commerce you may have full information of goods by visiting websites so that you can see the price version so that you can choose to buy that thing or not.

* Discount: some e-commerce companies put some discount on their product because the whole world wants to use cashless.

* Time management: recovering time used and transport to reach a physical location for example market or bank.

\section{Disadvantage}

* Thieves: There are thieves who use the Internet where they do some duplicate websites and use them to steal money from some clients who don't know how to differentiate fake websites and true websites.

* Quality: sometimes they may bring the different quality with what you need because they know that you can't bring it back to the market as long as it is very far.

* Trust: you cannot be sure if they will bring your good at time or not. 


\section{Conceptual framework}

Independent Variable

Electronic Commerce

* Electronic Ordering

* Using Mobile Phones

* Using Computers
Dependent Variables

Comprehensive Strategy

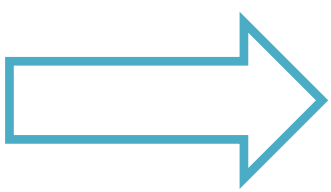

* Competitive Strategy

* Time saving

* Timely delivery

* Increase Customer Based

\section{RESEARCH DESIGN}

The study adopted a descriptive research design where descriptive statistics were applied to analyze data from questionnaires and interview guide. Descriptive research design allowed the researcher to study the elements in their natural form without making any alterations to them. This indicates that a case study research is good for contemporary events when the relevant behavior cannot be manipulated [11].

\section{POPULATION OF THE STUDY}

The population of interest in this research constitutes staff of Kikuu online Shopping Rwanda. In line with this, the target population was 130 employees working in finance, procurement, and distribution departments, in addition to management team.

\section{SAMPLE SIZE AND SAMPLING TECHNIQUES}

The sample size of the study was 98 respondents. To determine this sample, the researcher used the Solvin's sample size formula and it is shown below:

$$
\mathrm{n}=\frac{\mathrm{N}}{1+\mathrm{Ne}^{2}}
$$

Where $\mathrm{n}=$ the desired sample size $\mathrm{e}=$ probability of error (i.e., the desired precision, e.g., 0.05 for $95 \%$ confidence level) $\mathrm{N}=$ the estimate of the population size. Therefore: $\mathrm{N}=130$; $\mathrm{e}=0.05$

$$
n=\frac{130}{1+130(0.05)^{2}}=98 \text { Respondents }
$$

\section{RESEARCH FINDINGS AND DISCUSSION}

Table 1: Model Summary

\begin{tabular}{|c|c|c|c|c|}
\hline Model & $\mathrm{R}$ & $\mathrm{R}$ Square & Adjusted R Square & $\begin{array}{c}\text { Std. Error of } \\
\text { the Estimate }\end{array}$ \\
\hline 1 & $.868^{\mathrm{a}}$ & 0.752 & 0.779 & 19.371 \\
\hline \multicolumn{4}{|c}{ a. Predictors: (Constant), Electronic ordering } \\
\hline
\end{tabular}

The model summary indicated that an adjusted $\mathrm{R}$ squared is coefficient that determines the variation in the dependent variable due to changes in the independent variable as revealed in the table, the value of adjusted $\mathrm{R}$ squared was 0.752 , an indication that there was variation of $75.2 \%$ on strategy outcomes to changes electronic ordering, electronic billing and electronic payment. Findings revealed in the table show that $75.2 \%$ changes in strategy outcomes could be accounted on by electronic ordering has a strong positive impact between the study variables marked by $R=.752 \mathrm{a}$. 
Vol. 10, Issue 10, October 2021

DOI: $10.17148 /$ IJARCCE.2021.101029

Table 2: ANOVA

\begin{tabular}{|c|c|c|c|c|c|c|}
\hline \multicolumn{2}{|r|}{ Model } & $\begin{array}{c}\text { Sum of } \\
\text { Squares }\end{array}$ & Df & $\begin{array}{l}\text { Mean } \\
\text { Square }\end{array}$ & $\mathrm{F}$ & Sig. \\
\hline \multirow{3}{*}{1} & Regression & 1.624 & 1 & 0.421 & 3.613 & $.000^{\mathrm{b}}$ \\
\hline & Residual & 0.523 & 82 & 0.024 & & \\
\hline & Total & 2.23 & 83 & & & \\
\hline \multicolumn{7}{|c|}{ a. Dependent Variable: Strategy outcomes } \\
\hline & Dnod: & $(\mathrm{Co}$ & & 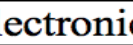 & ndan & \\
\hline
\end{tabular}

As revealed in the ANOVA test, a p-value of 0.000 less than alpha (5\%), the significance positive impact level. In addition, the results clarify that the given data perfect well with the multiple regression models. Therefore, the significance value was less than 0.05 , an indication that the model was statistically significant.

Table 3: Coefficients

\begin{tabular}{|c|c|c|c|c|c|c|}
\hline \multirow{2}{*}{ Model } & \multicolumn{2}{|c|}{$\begin{array}{c}\text { Unstandardized } \\
\text { Coefficients }\end{array}$} & $\begin{array}{c}\text { Standardized } \\
\text { Coefficients }\end{array}$ & \multirow{2}{*}{$\mathrm{T}$} & \multirow{2}{*}{ Sig. } \\
\cline { 2 - 5 } & B & Std. Error & Beta & & \\
\hline 1 & (Constant) & 1.854 & 1.543 & & 1.232 & 0.002 \\
\cline { 2 - 7 } & E-ordering & 0.826 & 0.233 & 0.526 & 2.256 & 0 \\
\hline \multicolumn{6}{|c|}{ a. Dependent Variable: Strategy outcomes } \\
\hline
\end{tabular}

From the data reached in the table, the established regression equation was the following: $\mathrm{Y}=1.854+0.826+\sum 0$

From the above regression equation it was revealed that holding electronic ordering. To note is that, a unit increase in E-ordering would lead to increase in strategy outcomes at Kikuu Online shopping Rwanda by a factor of 0.826 , a unit increase in e-ordering would lead to increase in strategy outcomes at Kikuu Rwanda by a factor of 0.826; and a unit increase in e-payment would lead to increase in strategy outcomes at Kikuu online shopping Rwanda by a factor of .826. In addition to the above, since earlier the study also found that all the p-values were less than 0.05 , this is a confirmation that all the variables were statistically significant in influencing e-commerce adoption by Kikuu Rwanda as a competitive strategy on its outcomes.

\section{CHALLENGES AND FINDINGS}

The rapid growth of online business transactions indicates that e-commerce over the Internet is an irreversible trend. Based on various reports from leading international consulting firms such as Forrester Research and International Data Corporation, it is predicted that B2B e-commerce will be worth as much as 7 trillion of US dollars in a few years, and B2C will also be worth over hundreds of billions of US dollars in the United States alone. Although e-commerce has huge potential, there are challenges for people in adopting e-commerce in their daily life. For example, in Hong Kong it was found that only $4 \%$ of Hong Kong Internet users bought goods or services or traded securities online, according to a recent survey conducted by the Census and Statistics Department of Hong Kong [6].

In the United States, according to E-Stats released by the Department of Commerce, retail e-sales were \$10 billion US dollars in the fourth quarter of 2001, about $1.2 \%$ of total retail sales in that quarter. In Europe, according to Data monitor, the size of the European online market in 2001 is about $\$ 3.23$ billion US dollars. What are the barriers that prevent e-commerce from reaching the mass market? A recent survey report shows that payment security is a major concern for online shopping.

Consumers are not willing to expose their credit card numbers online if they are not certain whether the numbers are securely transferred and saved. Another important issue is privacy [7] currently, online merchants usually require consumers to fill in detailed private information, including address and credit card information. Consumers do not like to have their shopping activities easily traceable. Consumers want easy access to premium content without the hassle of disclosing personal credit card information to unknown sites, or going through a tedious registration and authorization process.

The challenge of counterfeit currency and how it can be overcome 


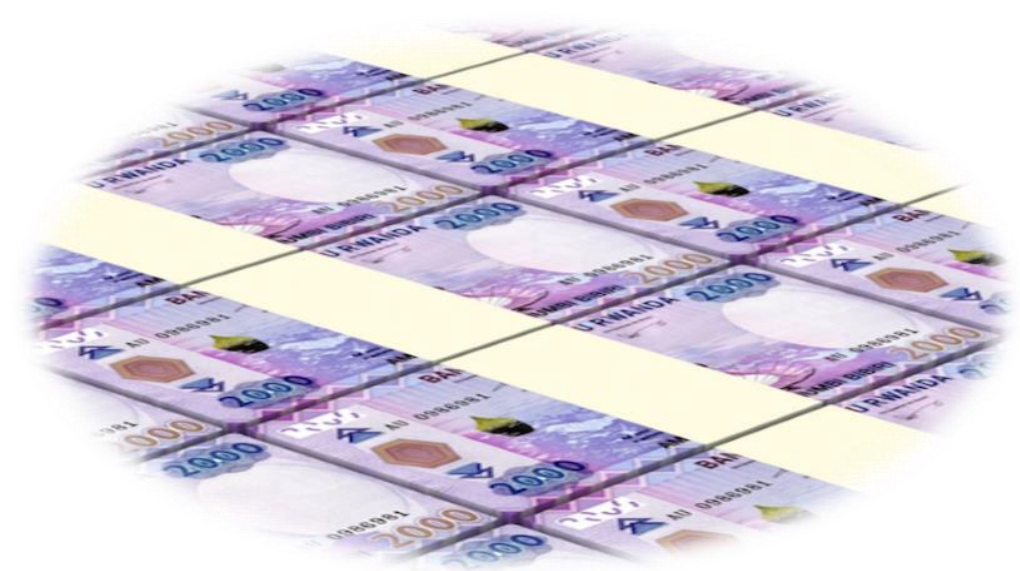

Figure.3: Counterfeit currency in Rwanda

Financial experts argue that overcoming counterfeit money in any given economy goes beyond only acquiring technology that examines money, but also building strong ties between law enforcers and the business community in order to collectively fight against the challenge.

"Criminals who spread counterfeit currency are not afraid of their money being detected. What they are scared of is being arrested. Therefore, coordination between police and residents is very important. Reporting a counterfeit case as soon as it occurs is the key to fighting it," Ernest Schema, a financial expert and holder of Masters in Accounting said in an interview. Another important aspect, according to Schema, is through education and sensitization campaigns aimed at engaging the masses and helping them understand the dangers associated with money counterfeit flows.

\section{General challenges}

The researcher figure out mainly challenges which faced by e-commerce as following:

* Uneducated people: in many countries there are still many people who are uneducated so that it cannot be possible for them to use e-commerce even if physical markets are very far, they manage to go there because they don't have another choice.

* Rural villages: people who live there use e-commerce on a low level because it cannot be easy to deliver their goods because of lack of infrastructures.

\# Lack of infrastructure: In the developing countries there is a problem of low infrastructure such as electricity power, Internet.

* Culture: some people have a culture of using physical money and buy physical goods.

* Charges fees: Clients need to get the best price they can like e-commerce.

\section{FINDINGS AND RESULT}

RNP has in the past worked with Rwandan residents through community policing, which has led to the arrest of criminals. Another expert, Board Chairman of National Bank of Rwanda, Hon.John Rwangobwa explained that money counterfeiting is a criminal offence and all stakeholders must come on board to ensure that this crime does not infiltrate the banking sector. The findings from Fin scope 2021 revealed that about $68 \%$ of adults in great lakes Region are formally in actions of Counterfeiting.

This static includes banked and unbanked formally included individuals. A key objective of the payment system is to move this statistic upwards to achieve $100 \%$ financial inclusion by 2020 . This document defines financial inclusion as indicated by the G-20's Global Partnership for Financial inclusion (GPFI). GPFI defines financial inclusion along three dimensions:

* Access to Vision to build a cashless Rwanda through a world-class payment system that is secure, reliable, efficient, scalable, innovative, and promotes financial inclusion and financial services.

* Usage of financial services, are better where you find peoples accessing the service, goods, with cash out by using cashless for example From April 2020 due the pandemic covid-19 people was not able to go to the physical bank means there were push and pull money through their home, it was not easy to access physical market as it was before due the lockdown.

Through this E-commerce which involves a cashless permit to pay and receive money electronically without moving to the local bank or physical institution for physical notes. 
* The quality of the products and services delivered to develop a payment system that is safe, reliable, and efficient for all participants in the ecosystem World-class payment systems must be safe, reliable, and efficient for all participants.

* These attributes of the payment system build consumer confidence in the system, which leads to increased patronage and overall development of the payment ecosystem.

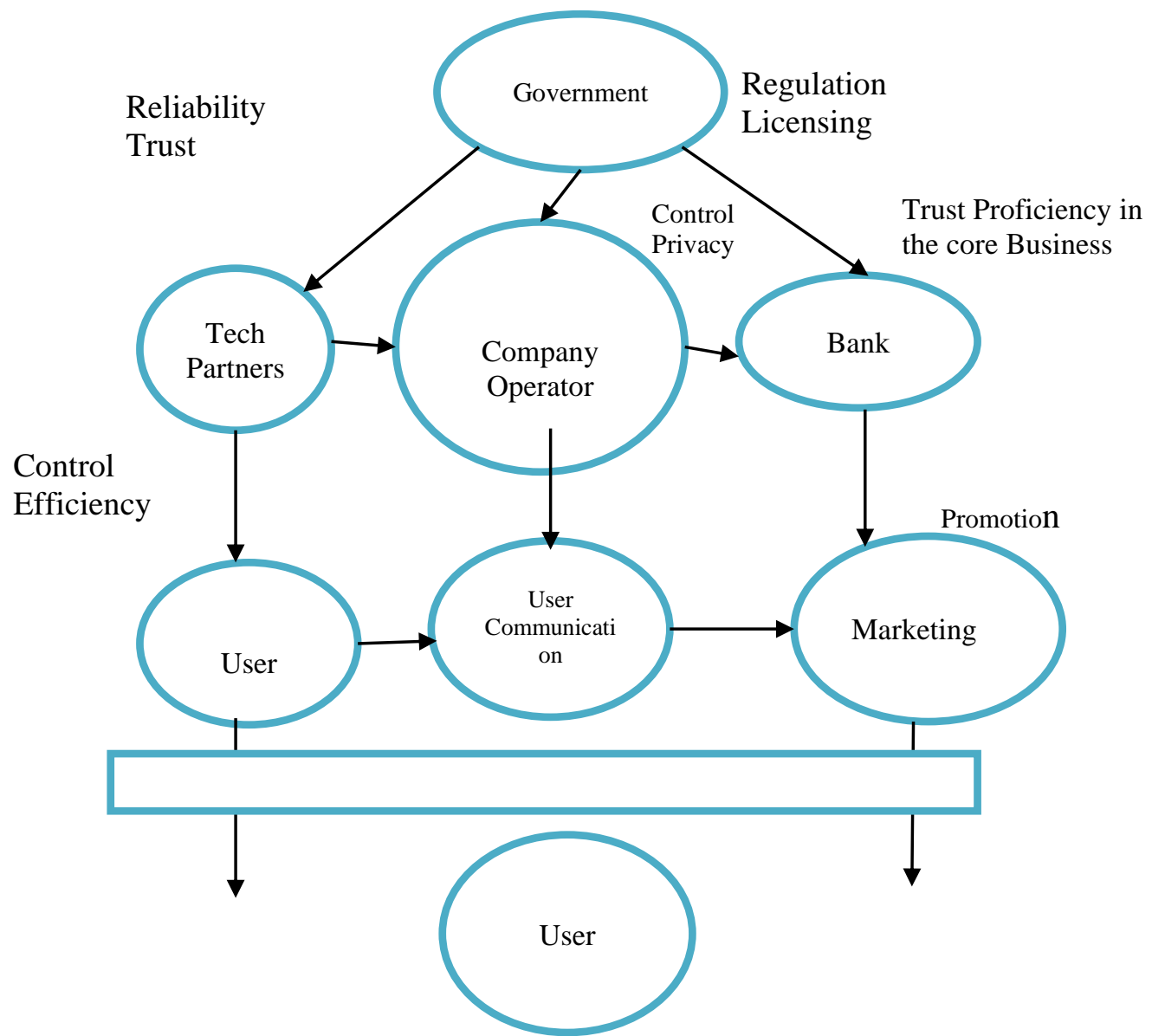

Figure2: Factors influencing user perception of online electronic payment systems.

The study detected two major factors including several sub factors such as marketing capabilities, social web pages, trust, ease of use, relationship with customers, access to information, information technology, etc., which influences emarketing. Perception toward e-payment [8] finds that a user's overall attitude toward a specific information technology (IT) and its applications are a major factor determining whether an individual uses that system. Accordingly, attitude toward use is also determined by perceived ease of use of that IT application [9], confirms this theory in his study where users' perception of e-payment has a significant effect on its acceptance, which is highly dependent on users' attitudes, [10] further states that prior adoption of IT had an identifiable impact because customers will usually adopt a new service only when they have similar experiences before. In addition, the feasibility of technology in terms of security, trust, and efficiency will also affect users' decision to use e-payment. Based upon these premises, attitude toward e-payment is operationalized in this study in terms of the perception that it is better than the traditional payment channels, that it can be trusted and is secure, easy to use, and efficient. The following subsections present the literature on the factors

Influencing e-payment. Benefits, Trust, Self-efficacy, ease to use, security. There is a significant relationship between security and consumers' perception toward e-payment. Figure 1 shows the schema research framework of this study. The five independent variables (security, trust, benefits, self-efficacy, and ease of use) are posited to have significant relationships with the dependent variable. 


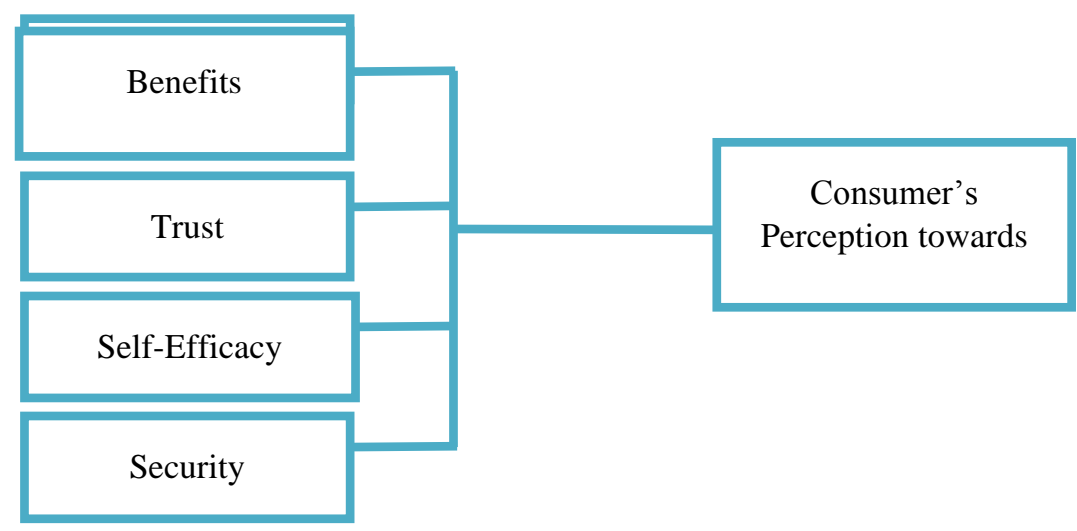

Figure3: Consumers' perception toward e-payment

\section{CONCLUSION}

In conclusion, electronic transfer funds have been around for many years and the economy has greatly benefited from this technological advance. An electronic payment system such as credit cards has facilitated monetary transactions and even provides a way to finance everyday purchases through credit. Because of this, bit coins are gaining popularity but there are still many questions and considerations of a virtual economy. However, the risk of identity thefts, market euphoria, and privacy issues will always exist. As history has shown us, new technology can cause irrational exuberance that only leads to overvalued securities and ultimately end in a financial collapse. Nonetheless, new financial technology is not yet perfected and can be very costly. But with new innovations and proper usage, financial technology can be the key to successfully managing one's money.

\section{RECOMMENDATIONS}

The research report will help the financial institutions to improve on their E banking and financial performance but most especially if they adopt optimal model as goodand its governance Policy, however for the case of Rwanda in spite of banks trying to enforce the e banking services it is still faced with some challenges which need to be addressed in order to promote effective and efficient banking performance and these are: The development of an efficient monetary transfer system in Rwanda has been hampered by so many factors. Rwanda is faced with infrastructural deficiency such as erratic power supply and communication link in some areas, inadequate skilled managers and requisite tools on end users and client systems, high charge or cost for the e-payment terminals (ATMs) so the banking legislation should set out standard charges for e-payment services. Hence these factors are believed to hinder e-banking services performance in the country hence affecting banks performance.

It should also be noted no substantial academic research has been done in Rwanda especially on performance of commercial banks hence the researcher would like to examine the impact of e banking on performance of commercial banks in Rwanda despite of the above factors in order to come up with recommendations to improve on e-banking services in the country.

\section{REFERENCES}

[1] Markopoulos, P. and Ungar, L., 2002. Selling price information in e-commerce. U.S. Patent Application $09 / 813,389$.

[2] Gambacorta, Leonardo. "Asymmetric bank lending channels and ECB monetary policy." Economic Modeling 20.1 (2003): 25-46.

[3] Slozko, Olena, and Anna Pelo. "The electronic payments as a major factor for further economic development." Economics \& Sociology, 7.3 (2014): 130.

[4] Naughton, S. H. (2016). Developing an Agile Supply Chain Model for SMEs (Doctoral dissertation, University of Liverpool).

[5] Laudon, Kenneth C., and Carol Guercio Traver. "The revolution is just beginning." E-commerce: Business, Technology, and Society (2002): 2-53.

[6] Philippsohn, Steven, and Samantha Thomas. "E-fraud-what companies face today. "? Computer Fraud \& Security 2003.1 (2003): 7-9.

[7] Li, Yingchun, Danqi Li, and Chuangzhou Wu. "A new shear strength criterion of three-dimensional rock joints." Rock Mechanics and Rock Engineering 53.3 (2020): 1477-1483. 
[8] Taylor, Shirley, and Peter Todd. "Assessing IT usage: The role of prior experience." MIS quarterly (1995): 561 570 .

[9] Abrazhevich, Dennis. "Classification and characteristics of electronic payment systems." International Conference on Electronic Commerce and Web Technologies. Springer, Berlin, Heidelberg, 2001.

[10] Eastin, Matthew S. "Diffusion of e-commerce: an analysis of the adoption of four e-commerce activities." Telematics and informatics 19.3 (2002): 251-267.

[11] Rowley, Jennifer. "Conducting research interviews." Management research review (2012). 